\title{
THE AGS BOOSTER HEAVY ION OPERATION
}

\section{Booster Technical Note}

No. 61

\author{
Y, Y, LEE \\ September 3, 1986
}

\section{ACCELERATOR DEVELOPMENT DEPARTMENT \\ Brookhaven National Laboratory \\ Upton, N.Y. 11973}


THE AGS BOOSTER HEAVY ION OPERATION

Y. Y. Lee

September 3, 1986

In this note we propose a mode of the AGS and the Booster operation. It has been decided the transfer line between the Booster and the AGS shall be capable of transporting the beam of 11 tesla-meter of magnetic rigidity which corresponds to $2.5 \mathrm{GeV}$ proton. The line is not capable of transport lighter ion species if they are accelerated to the full capability of the Booster of 17.58 T-m. Therefore, we should decide the energy of the each species compatible with the capability of together components of the system. the proton in the Booster nominally accelerate to $7.51 \mathrm{~T}-\mathrm{m}$, and the final magnetic rigidity of gold ion is 17.58 $\mathrm{T}-\mathrm{m}$ in the Booster and $7.343 \mathrm{~T}-\mathrm{m}$ in the AGS after stripping. A mode of operation we would like to propose is that all heavy ions to be accelerated to magnetic rigidity in the AaS to 7.343 Testa-meter. The energy is high enough to give better than or equal to 50\% stripping efficiency for the gold and over $90 \%$ for iodine or lower ion species. The magnetic and RF parameters for this scheme is given in the table. The RF parameter in the table is consistent with the Booster Tech Note 52. The times in the table are from start of the RF turn on for the bunching. The times are approximate, but may be useful to calculate the duty factors of the equipment. Also given are RF bunching voltage for .05 $\mathrm{eV}-\mathrm{sec} / \mathrm{amu} / \mathrm{bucket}$ and $\mathrm{RF}$ accelerating voltage required to run the program of the Booster Tech. Note 52 and above mentioned program. The numbers for proton are given for comparison. 
TAELE

\begin{tabular}{|c|c|c|c|c|c|c|}
\hline & $A \cup$ & I & $\mathrm{Cu}$ & $S$ & c & $P$ \\
\hline$B P(A G S)$ & & & 7.343 & & & 7.51 \\
\hline $3 p$ (BOOSTER) & 17.58 & 13.42 & $10.1 \leq$ & 8.39 & 7.343 & 7.51 \\
\hline$B(K-G)$ & 12.8 & 9.8 & 7.4 & 6.1 & 5.3 & 5.5 \\
\hline K.E/amu MeV & 350. & 375. & $=32$. & $5,0$. & 508. & 1500 . \\
\hline$=(\overline{R F}) \mathrm{MHZ}$ & 3.054 & $3.21 E$ & 3.246 & 3.392 & 3.392 & 4.114 \\
\hline$B(2 n j)$ & .028 & $.50 i$ & .556 & .522 & .577 & 1.563 \\
\hline $\mathrm{B}(.69 \mathrm{MHz})$ & 2.13 & $1.5 e$ & $\therefore .58$ & .81 & .71 & $\cdots-$ \\
\hline$B(2.4 \mathrm{MHZ})$ & 8.68 & 6.37 & $\therefore .45$ & $\Xi .32$ & 2.92 & $\cdots$ \\
\hline $\mathrm{T}(.69 \mathrm{MHz}) \mathrm{ms}$ & 68. & 55. & $\leq s$. & 23. & 21. & --- \\
\hline$T(2.4 M H z) m s$ & 316. & 297. & 273 & 236 & 235. & $-\cdots$ \\
\hline$V($ bunch) $K V$ & .877 & .652 & .445 & .332 & .288 & $-\cdots$ \\
\hline viace; $\quad k v$ & 14.6 & 9.5 & 8.6 & $\varepsilon .7$ & 5.7 & $\ldots$ \\
\hline
\end{tabular}

